\title{
СОЦИОЛОГИЯ
}

И СОЦИАЛЬНЫЕ ТЕХНОЛОГИИ

DOI: https://doi.org/10.15688/lp.jvolsu.2017.4.4

UDC 316.334 .23

LBC 60.561 .22

\section{SOCIAL ENTREPRENEURSHIP AS A FORM OF ACTIVISM IN THE CONTEXT OF SOCIAL POLICY REFORM IN RUSSIA ${ }^{1}$}

\author{
Elena G. Vasilyeva \\ Volgograd State University, Volgograd, Russian Federation \\ Mariya B. Poltavskaya \\ Volgograd State University, Volgograd, Russian Federation
}

\begin{abstract}
The article discusses the peculiarities of non-profit sector institutionalization in modern Russian society. Legislative regulations governing the activities of non-profit organizations as well as changes in the concept / strategy of state social policy have a decisive influence. Innovations in the legislation are connected with the legislative regulation of the organizational and legal form of socially-oriented non-profit organization. Guarantees of state support in the form of subsidies are provided for such organizations. As a result, new institutional conditions for the development of the non-profit sector are created. The article reveals the tendencies of development of non-profit sector: there is a significant increase in the number of organizations of social orientation while the share of organizations of social orientation decreases and the share of organizations aimed at solving the problems of local community (territorial self-government organizations) increases; there are institutional limitations related to the lack of procedures for certification and licensing of socially oriented organizations; the main mechanisms for the distribution of social transfers are the mechanisms of competitive selection and social financing; while the strategic directions of financing (state support) of social projects of NGOs are only beginning to be determined on the basis of public conventions. The article discusses the key institutional changes in the social sphere in the period from 2004 to 2017 affecting NGOs: autonomy of social institutions; formation of social standards, administrative regulations of services; inclusion of NGOs in the provision of social services and others. The need to attract non-governmental sources of financing creates new prospects for the development of the social market of 굴 social services through the development of social entrepreneurship. Social entrepreneurship is considered from the standpoint of the theories of the public good and the economy of the public sector as well as the $\sum_{i}$ theory of rational management. New aspects in the understanding of social entrepreneurship are connected with the distinction between the economic and entrepreneurial aspects of the organizations activities; the idea of determining the impact of targeted strategies and project forms of activity; the identification of signs of the organization of entrepreneurial type.

Key words: social entrepreneurship, technology of social entrepreneurship, methodology of social entrepreneurship, economy of the non-profit sector, organizational and legal form of a non-profit organization, a socially-oriented non-profit organization, social policy in the Russian Federation.
\end{abstract}


УДК 316.334 .23

ББК 60.561 .22

\title{
СОЦИАЛЬНОЕ ПРЕДПРИНИМАТЕЛЬСТВО КАК ФОРМА АКТИВИЗМА В УСЛОВИЯХ РЕФОРМЫ СОЦИАЛЬНОЙ ПОЛИТИКИ В РОССИИ ${ }^{1}$
}

\author{
Елена Геральдовна Васильева \\ Волгоградский государственный университет, г. Волгоград, Российская Федерация \\ Мария Борисовна Полтавская \\ Волгоградский государственный университет, г. Волгоград, Российская Федерация
}

\begin{abstract}
Аннотация. В статье рассматриваются особенности институционализации некоммерческого сектора в современном российском обществе. Определяющее влияние оказывают: законодательные регламентации деятельности организаций некоммерческого сектора, а также изменение концепции/стратегии государственной социальной политики. Инновации в законодательстве связаны с законодательной регламентацией такой организационно-правовой формы, как социально ориентированная некоммерческая организация. Для таких организаций обеспечены гарантии государственной поддержки в форме субсидирования. Вследствие этого создаются новые институциональные условия развития некоммерческого сектора. В статье выявляются тенденции развития некоммерческого сектора: наблюдается значительный рост численности организаций социальной направленности, при этом уменьшается доля организаций общественно-гражданской направленности и увеличивается доля организаций, направленных на решение проблем локального местного сообщества (территориальных организаций самоуправления); существуют институциональные ограничения, связанные с отсутствием процедур сертификации и лицензирования социально ориентированных организаций; основными механизмами распределения социальных трансфертов являются механизмы конкурсного отбора и социального финансирования; при этом стратегические направления финансирования (государственной поддержки) социальных проектов НКО только начинают определяться на основе общественных конвенций. В статье рассматриваются ключевые институциональные изменения в социальной сфере в период с 2004 по 2017 г., которые влияют на НКО: автономизация деятельности учреждений социальной сферы; формирование социальных стандартов, административных регламентов услуг; включение НКО в процессы предоставления социальных услуг и др. Необходимость привлечения негосударственных источников финансирования создает новые перспективы для развития рынка социальных услуг на основе развития социального предпринимательства. Социальное предпринимательство рассматривается с позиций теорий общественного блага и экономики общественного сектора, а также теории рационального управления. Новые моменты в понимании социального предпринимательства связаны с разграничением экономического и предпринимательского аспектов деятельности организаций; идеей определяющего влияния целевых стратегий и проектных форм деятельности; выявлением признаков организации предпринимательского типа.

Ключевые слова: социальное предпринимательство, технология социального предпринимательства, методология социального предпринимательства, экономика некоммерческого сектора, организационно-правовая форма некоммерческой организации, социально ориентированная некоммерческая организация, социальная политика в РФ.
\end{abstract}

Феномен социального предпринимательства привлекает внимание современных исследователей как одна из наиболее ярких форм проявления социальной активности. Для нас наиболее важными являются исследования методологической направленности, представленные в публикациях J.C. Short, T.W. Moss, G.T. Lumpkin [11] и M. Dacin, P. Dacin, P. Tracey [8], где социальное предпринимательство представлено через концепт социальной пользы, а также исследования
J. Mair, I. Marty [9] и P. Murphy, S. Coombes [10], где рассматриваются институциональные модели социального предпринимательства. Среди российских разработок по социальному предпринимательству обращают на себя внимание публикации Н.Ф. Кадол, где социальное предпринимательство рассматривается в контексте рыночной экономики [3]; Я.С. Гришиной, посвященные законодательному регулированию деятельности социальных предпринимателей [2]; Т.Г. Калугиной [4] и 
А.А. Московской [6], обобщающей особенности практики социального предпринимательства в современной России. Необходимо отметить, что в данной статье развиваются идеи, высказываемые ранее авторами в публикациях, посвященных проблемам социальной политики [1] и социального предпринимательства [7], которые, будучи интегрированными, дают возможность выявить наиболее существенные особенности современного некоммерческого сектора в российском обществе и обозначить тенденции его последующего развития.

Исследование социального предпринимательства в контексте реформирования социальной сферы и институционализации новых организационных форм деятельности некоммерческих организаций (далее - НКО) в современном российском обществе является новым и малоизученным аспектом междисциплинарной проблематики, находящейся на пересечении традиционного экономического, социологического и политико-правового подходов. В этом случае на первый план выходит переоценка роли НКО в решении проблем социальной политики, а значение социального предпринимательства определяется в связи с созданием институциональных структур и механизмов функционирования социального рынка.

В широком понимании социальное предпринимательство выступает как форма позитивного социального активизма, приносящая общественную пользу [10, p. 327]. Социальное предпринимательство - это принятие на себя миссии создания и поддержания социального блага [7, с. 137]. В этом смысле по целевому содержанию деятельности оно совпадает с понятием «социально ориентированная некоммерческая организация» (далее - $\mathrm{CO}$ НКО). В то же время наиболее часто цитируемые определения социального предпринимательства подчеркивают следующее: социальное предпринимательство - это социальная активность в формате бизнеса или бизнес, ориентированный на решение социальной проблемы, а не на прибыль [9, р. 38]. В данном случае фиксируются существенные признаки феномена и новые организационные аспекты социально ориентированной деятельности НКО, которые являются важными для понимания институциональных тенденций развития НКО в современной России в условиях реформирования социальной сферы.

Характеризуя процесс институционализации, следует подчеркнуть определяющее влияние законодательно-нормативной регламентации правового статуса НКО в Федеральном законе «О некоммерческих организацияХ» (№ 7-ФЗ от 12.01.1996, ред. от 14.11.2017), а также регламентации новой организационно-правовой формы - социально-ориентированной некоммерческой организации в Федеральном законе «О внесении изменений в отдельные законодательные акты Российской Федерации по вопросу государственной поддержки социально ориентированных некоммерческих организаций» (№ 40-Ф3 от 05.04.2010 (ред. от 19.09.2017). Институциональное влияние нового организационного формата определяется тем, что он фиксирует целевое содержание деятельности НКО через социальные приоритеты (а не, например, гражданско-политические интересы или бизнесцели), посредством чего обеспечивается их правовая трактовка в качестве институтов, интегрированных в решение проблем социальной сферы, то есть выражающих интересы различных субъектов социальной политики. Кроме того, в в ст. 2 и ст. 3.1 закона о социально ориентированных некоммерческих организациях особо регламентируются направления деятельности, определяющие их функциональную специфику и обеспечивающие нормативные основания государственной поддержки. Указанные направления, с одной стороны, совпадают с наиболее важными, имеющими общественную значимость проблемами социальной сферы и, с другой стороны, определяются задачами государственной социальной политики.

Благодаря законодательным инновациям формируется иное нормативно-ценностное основание для регулирования некоммерческого сектора. При этом в сравнении с прежними политико-правовыми трактовками общественная значимость НКО определяется не столько идеей гражданского общества, сколько идеей социального государства. Позитивное правовое содержание обеспечивается посредством разграничения различных типов НКО, конкретизации их профессиональных функций, а 
также регламентации целевых приоритетов деятельности, исходя из стратегии и задач государственной социальной политики. Изменения в законодательстве соответствуют фактическим тенденциям процесса институционализации некоммерческого сектора в постперестроечной России, а также в целом отражают социально-исторические традиции и массовые требования в отношении деятельности общественных организаций. В этой связи показательно, что формат СО НКО не вызвал особой дискуссии и значимой критики ни со стороны экспертного сообщества, ни со стороны самих организаций некоммерческого сектора.

Согласно официальным статистическим данным, из 4744 НКО Волгоградской области не менее 2922 организаций (62\%) относятся к СО НКО. При этом отбор СО НКО учитывает 31 направление деятельности организаций, соотносимое со сферами социальной поддержки, благотворительности, охраны окружающей среды и здоровья, культурно-образовательной и просветительской деятельностью, а также решением иных гуманитарных проблем [5]. Данные официальной статистики фиксируют увеличение доли некоммерческих организаций в общем числе организаций некоммерческого сектора по сравнению с общественными объединениями: в 2010-2012 гг. она составила 49\%, в 2013-2015 гг. - $51 \%$, в 2016-2017 гг. - 53 \%. Показательно, что динамика структурных изменений НКО связана с ростом численности автономных некоммерческих организаций, некоммерческих фондов, некоммерческих партнерств, некоммерческих учреждений и в особенности территориальных организаций самоуправления. Данные организации характеризуются «многопрофильностью» целевых функции и вследствие этого в большей степени ориентированы на поиск негосударственных источников финансирования и создание собственных социальных резервов, а также на большую автономность действия на основе использования сетевых коммуникаций.

Обобщение данных государственной и ведомственной статистики, в том числе данных федеральных и региональных исполнительных властных структур, показывает, что численность СО НКО варьируется в зависи- мости от ведомственных критериев их оценки в значительном диапазоне - от 27 до 514 и 2 922(!) ${ }^{2}$. В ведомственных реестрах к СО НКО могут быть отнесены организации-поставщики социальных услуг, организации-получатели субсидий из государственного и муниципальных бюджетов, организации-победители конкурсов социальных проектов или подведомственные учреждения, реализующие государственный заказ (в основном в сфере социальной защиты и поддержки населения) и даже различные «списочные составы» общественных объединений, формируемые целевым образом исполнительными органами власти ${ }^{3}$. Это указывает на недостаточную «отработанность» процедур формально-правовой квалификации организаций некоммерческого сектора и их отнесения к СО НКО. Предложенный в законодательстве формат фиксирует в большей степени стратегическое целевое содержание деятельности НКО и нуждается в конкретизации с учетом практических проблем организационно-правового взаимодействия институциональных структур, интегрированных в решение вопросов социальной сферы.

Необходимость совершенствования формата СО НКО диктуется также новыми практиками деятельности организаций некоммерческого сектора, связанными с решением современных задач государственной социальной политики. Реформирование социальной сферы реализуется в рамках управленческой стратегии эффективной социальной политики и предполагает формирование сервисного социального государства и развитого рынка социальных услуг. Применительно к некоммерческому сектору можно выделить два этапа реализации указанной стратегии.

На первом этапе, ориентировочно в период с 2005 по 2014 г., реформа соотносилась, во-первых, с автономизацией учреждений социальной сферы, а также их институциональной трансформацией, связанной с переходом от «функциональной деятельности» к «производству социальных услуг». Во-вторых, она предполагала формирование дополнительной негосударственной институциональной подсистемы, обеспечивающей более широкое вовлечение населения в решение социальных проблем (массовое социальное участие) на ос- 
нове включения организаций некоммерческого сектора и развития гражданских волонтерских инициатив [1, с. 28]. В-третьих, что особенно важно, реформирование было направлено на создание элементов социального рынка посредством отработки институционального механизма, обеспечивающего выполнение государством функций социального регулятора процессов развития социальной сферы, в частности, на основе внедрения новых социально-управленческих технологий - проектного бюджетного финансирования, системы государственного (муниципального) заказа, конкурсного отбора поставщиков социальных услуг и грантового субсидирования. При этом использование рыночных элементов было ограниченным, а основные результаты были связаны с перераспределением функциональных полномочий, уровней ответственности и профессиональных компетенций структур, включенных в процесс предоставления социальных услуг. Это нашло отражение в создании национальных социальных стандартов, развитии отраслевых профессиональных стандартов, систем сертификации качества и административно-организационных регламентов, технологизирующих процесс производства (управления, предоставления) социальных услуг.

На современном этапе стратегия эффективной социальной политики определяется принципом оптимального использования общественных ресурсов на основе продвижения результативных социальных и управленческих технологий и поддержки институциональных инноваций, обеспечивающих решение социальных проблем на основе негосударственных источников финансирования. Это предполагает, во-первых, переход от «социального сервисного государства» к «социальному рыночному государству» (или еще большее использование элементов рыночного регулирования в государственном управлении и развитии социальной сферы), а также нормативно-законодательное обеспечение социального рынка как основного институционального механизма реализации социальных услуг. Во-вторых, это предполагает расширение круга субъектов социальной политики на основе вовлечения новых акторов и создания дополнительных структур институционального взаимодействия. Данная задача решается как посред- ством дифференциации институциональных структур, связанных с производством и предоставлением социальных услуг (дальнейшим развитием негосударственных некоммерческих учреждений сферы образования, здравоохранения, социальной поддержки, ЖКХ и др.), так и посредством дифференциации регуляторов социального рынка на основе создания дополнительной негосударственной институциональной структуры, аккумулирующей социальные резервы (финансовые, организационные, информационные, волонтерские ресурсы) и обеспечивающей движение инвестиции на рынке социальных услуг (стратегические институты развития, целевые фонды, ресурсные центры, проектные инициативы и др.). В-третьих, это предполагает формирование институциональных механизмов, обеспечивающих конкурентоспособность НКО в качестве участников социального рынка на основе целевой поддержки социально-инновационных направлений деятельности, продвижения эффективных технологий производства социальных услуг и, что особенно важно, использования негосударственных источников финансирования и создания собственных ресурсов.

Формирование социального рынка определяет и необходимость дальнейшего развития организационных форм деятельности НКО, в том числе на основе интеграции идеи социального предпринимательства. Новые моменты в концептуализации темы, позволяющие зафиксировать специфические признаки формата социального предпринимательства, связаны с разграничением экономического и социального содержания деятельности $\mathrm{CO} \mathrm{HКО} \mathrm{[3,} \mathrm{с.} \mathrm{10].} \mathrm{Экономический} \mathrm{аспект} \mathrm{свя-}$ зан с ролью НКО как субъектов некоммерческого сектора экономики (их производственной, хозяйственной, финансовой деятельностью), а социальный - с особенностями институциональных практик, предполагающих использование социального предпринимательства в качестве эффективной социально-управленческой технологии. Социальное предпринимательство - это, прежде всего, социальное рыночное управление экономикой некоммерческого сектора, включающее организацию деятельности субъектов в качестве участников системы общественного воспроизводства, направленного на создание особых 
продуктов и услуг - социальных благ, а также его технологическую оптимизацию в соответствии с правилами бизнес-процессов.

Методологической основой концепции социального предпринимательства служит управленческая парадигма социально-рыночной экономики, трансформировавшая и одновременно интегрировавшая традиционные концепции абсолютного рынка и государства всеобщего благоденствия [8]. При этом позитивноеценностное содержание данных концепций, отражаемое понятиями «предпринимательская инициатива» и «общественное благо», соотносится с экономикой общественного (некоммерческого, третьего) сектора, выступающей одним из компонентов инфраструктуры публичной сферы общественной жизнедеятельности наряду с гражданско-политическим и социально-культурным компонентами.

Экономика общественного сектора - это система производства, обмена и распределения социально значимой продукции и/или услуг, относящихся к особой группе потребительских благ. Понятие благо здесь рассматривается в рамках оппозиции «общественное - корпоративное / частное благо» и содержит отсылку к целевому содержанию исторического процесса экономического развития, трансформирующую собственно экономическое понимание общественного блага как потребительского блага. В этом смысле оно рассматривается с точки зрения социального (цивилизационного) прогресса и определяется социетальными императивами, которые выступают в качестве приоритетных по отношению к собственно экономическим категориям. Так, например, ценности общественной солидарности и государства всеобщего благоденствия неизбежно трансформируют идеалы свободного рынка, а понятия «экономический рост», «рыночная конкуренция», «максимизация прибыли» уточняются под влиянием понятий «социальный капитал», «социально-рыночные регуляторы», «социальная миссия компании» [11]. Соответственно, дифференцируется оценка предпринимательской рыночной деятельности: с одной стороны, как участия в создании непосредственных потребительских благ (продуктов и услуг), а с другой - как участия в создании совокупного общественного блага, то есть с точки зрения социального эффекта (последствий, риска данной деятельности).

В основе такого понимания содержится общественный интерес в устойчивом экономическом развитии, а само совокупное общественное благо трактуется в качестве стратегической цели рыночной предпринимательской деятельности. Данное благо, прежде всего, обеспечивает условия воспроизводства социального и культурного капитала, что соответствует потребности в общественноэкономическом воспроизводстве и поддержании общественной солидарности. Особенностью создания данного блага также является то, что, выражая коллективный социальный интерес, оно предполагает открытость и прозрачность процессов его создания и потребления или публичный характер взаимодействия субъектов, включенных в данные процессы.

Формирование социально-рыночных императивов оценки экономического развития оказывает, таким образом, существенное влияние на трансформацию частной формы экономической деятельности участников рынка в общественно-публичную форму. Это проявляется в организационно-управленческих инновациях сферы бизнеса, связанных с внедрением стандартов качества, принципов социальной ответственности и требований публичной отчетности. Но в наибольшей степени указанные изменения касаются все же экономики третьего сектора, применительно к которой и возможно рассматривать феномен социального предпринимательства. Так, современные международно-правовые модели социального предпринимательства включают такие организационные формы, как социальный кооператив, компания с социальной миссией, компания общественных интересов, социально ориентированная НКО [2, с. 112].

Практический, или инструментальный, подход к социальному предпринимательству выражается в его трактовке как эффективной социально-управленческой технологии [4, c. 95]. Данный подход основан на идеях функциональной социальной политики и рационального управления. В общем плане он исходит из возможности конвертации различных общественных интересов в систему социального рыночного обмена, исходя из организации про- 
цессов функционирования социальной сферы как процесса производства общественных/потребительских благ. Функциональность предполагает, что цели социальной политики объективируются, во-первых, в процессе институциональных взаимодействий групп и институтов, выражающих и реализующих различные общественные интересы посредством социальных инициатив, а во-вторых, под влиянием функциональных императивов, задаваемых социальными и рыночными регуляторами (интересы государства и механизмы рыночной конкуренции). Принцип рациональности предполагает менеджериализацию управления социальной сферой, исходя из требований эффективности отбора/реализации социальных инициатив и использования социальных ресурсов, а также на основе денежно-стоимостной калькуляции производимых общественных благ и затрачиваемых ресурсов. Применительно к деятельности НКО данные требования реализуются, прежде всего, в инструментальном плане, включающем стандартизацию и бизнес-оптимизацию профессиональных практик и поддержку инноваций в рамках проектного подхода (стратегическое планирование, управление по целям и задачам, ресурсный подход, финансовая калькуляция и оценка результативности и эффективности) [6, с. 75].

Следует подчеркнуть, что экономика некоммерческого сектора связана с общественно значимой экономической деятельностью, то есть деятельностью, направленной на развитие социального и культурного капитала общества и выражающей коллективный социальный интерес/группы интересов. Экономическим содержанием данной деятельности является создание потребительских благ, обеспечивающих потребности развития социальной сферы в самом широком смысле, в том числе в соответствии с целевыми задачами и направлениями социальной политики общества (здравоохранение, образование, социальная защита населения, ЖКХ, городская инфраструктура и др.); в соответствии с потребностями получателей услуг - целевых групп «конечных потребителей»; а также (что и открывает перспективу для проявления предпринимательской инициативы) в соответствии с функционалом организаций и предприятий, профессионально задействованных в данной сфере (производящих и реализующих продукты/услуги).

Исходя из особенностей функционирования экономики некоммерческого сектора, а также множества институтов и групп (организаций и учреждений, предприятий и инициатив), включенных в процесс создания совокупного общественного блага, необходимо, на наш взгляд, разграничение экономической и предпринимательской деятельности в социальной сфере. Это позволяет сформулировать специфические характеристики социального предпринимательства применительно к некоммерческому сектору, что, в свою очередь, может быть продуктивным для более совершенной правовой категоризации организационных форматов СО НКО с учетом новых тенденций развития социальной сферы.

Так, основными субъектами экономической деятельности в некоммерческом секторе являются участники рынка социальных услуг: некоммерческие организации, непосредственно включенные в производство общественных благ как потребительских благ, предоставляющие социальные услуги различным категориям пользователей; коммерческие организации, включенные в производство услуг в качестве поставщиков материальных ресурсов и ограниченные в получении прибыли; некоммерческие и коммерческие организации, выступающие инвесторами социального рынка. В то же время, поскольку функционирование социального рынка задается нерыночными регуляторами, содержание предпринимательского компонента определяется в большей мере признаками, имеющими отношение к стратегическому целевому содержанию деятельности участников социального рынка.

Систематизируя вышеизложенные характеристики и существенные признаки, социальное предпринимательство можно определить как:

- социальный менеджмент (эффективное социальное управление);

- социальное предприятие (целевой социальный проект, программа, инициатива, направленные на решение актуальных проблем, улучшение условий жизнедеятельности различных групп или общества в целом);

- социальную инновационную деятельность (форму гражданского участия, основанную на продвижении идей); 
- организационную форму социально-рыночной компании (компании, продвигающей на социальном рынке общественно значимые продукты или услуги);

- социально ориентированную бизнесстратегию (экономическую деятельность, реализуемую в соответствии с принципом социальной ответственности).

Данные компоненты определяют специфику НКО как субъектов социального предпринимательства и одновременно субъектов некоммерческого сектора экономики. Более того, отражая «социальное измерение» экономической деятельности, данные признаки позволяют оценивать организации некоммерческого сектора (а в перспективе и организации «большого бизнеса») как участников системы совокупного общественного воспроизводства социально значимых благ или в качестве субъектов социальной политики, приносящих или не приносящих общественную пользу.

Приведенные концептуализации, на наш взгляд, выступают перспективным основанием для дальнейшей законодательно-нормативной разработки форматов деятельности коммерческих и некоммерческих структур, отвечающих требованиям эффективной государственной социальной политики.

\section{ПРИМЕЧАНИЯ}

1 Работа выполнена в рамках научного проекта № 17-13-34010 «Ресурсный потенциал некоммерческих организаций в сфере социального предпринимательства» при финансовой поддержке РФФИ и Администрации Волгоградской области.

${ }^{2}$ Обращает на себя внимание различие данных о численности СО НКО, приводимых официальной и ведомственной, федеральной и региональной статистикой. Так, на 20.11.2017 в реестрах Министерства юстиции РФ и Министерства экономического развития РФ приводятся данные по численности региональных НКО (4 127 и 4871 соответственно), но в отношении СО НКО такая информация либо отсутствует (Министерство юстиции, например, формирует отдельный реестр НКО - исполнителей общественно полезных услуг, в который включено в настоящий момент «всего» 45 организаций, причем организаций, представляющих Волгоградскую область в данном реестре нет), либо численность СО НКО значительно отличается от численности, представленной ранее (так, реестр НКО Министерства экономического развития, фик- сирующий дополнительный подмассив СО НКО на основании критериев Ф3-40 (п. 3.1), включает «всего» 27 организаций). В Ежегодном докладе Минэкономразвития, посвященном СО НКО, в 2016 г. содержится информация о 30 организациях, при этом в качестве основного критерия их фиксации выступают переданные бюджеты по исполнению государственных социальных услуг.

${ }^{3}$ На региональном уровне на момент исследования (20.11.2017) данные о СО НКО представлены на официальном информационном портале областной администрации в виде нескольких ведомственных реестров или информационных сведений, целевых перечней/списков организаций, в том числе Реестр поставщиков социальных услуг Волгоградской области комитета социальной защиты и поддержки населения (включает 172 организации); Сведения о СО НКО - получателях поддержки и Сведения о ТОСах комитета по делам территориальных образований, внутренней и информационной политики (включают 400 и 1993 организации, соответственно); Реестр молодежных и детских общественных объединений, пользующихся государственной поддержкой в Волгоградской области, комитета по делам молодежи (включает 31 организацию; в настоящий момент данный комитет включен в состав комитета по образованию); Список национальных общественных объединений, осуществляющих деятельность на территории области, комитета по делам национальности и казачества (включает 107 казачьих сообществ); Сведения информационного ресурса «СО НКО Волгоградской области», являющегося частью официального информационного портала Волгоградской области (включают 514 организаций, в том числе ветеранских - 26, местных/муниципальных СО НКО - 411, областных СО НКО - 77).

\section{СПИСОК ЛИТЕРАТУРЫ}

1. Васильева, Е. Г. «Социальное государство» и новая модель социальной политики в России / Е. Г. Васильева // Власть. - 2008. - № 11. - С. 27-30.

2. Гришина, Я. С. Сравнительно-правовое исследование социального предпринимательства в странах Америки и Европы / Я. С. Гришина // Вестник Пермского университета. Юридические науки. 2012. - Вып. 2(16). - С. 111-121.

3. Кадол, Н. Ф. Социальное предпринимательство в рыночной экономике / Н. Ф. Кадол. - Брянск : Дельта, 2009. - 148 с.

4. Калугина, Т. Г. Социальное предпринимательство как фактор регионального развития (теория и практика) / Т. Г. Калугина // Регионы и региональное развитие. Серия «Политология. Религиоведение». - 2012. - № 2 (9), ч. 2. - С. 92-102. 
5. Комитет по делам территориальных образований, внутренней и информационной политики Волгоградской области. Информация. - Электpoн. текстовые дан. - Режим доступа: http://uprt. volgograd.ru/current-activity/statistics/information/ (дата обращения: 20.11.2017). - Загл. с экрана.

6. Московская, А. А. Социальное предпринимательство в России и в мире: практика и исследования / А. А. Московская. - М. : Изд. дом НИУ ВШЭ, 2011. $-288 \mathrm{c}$.

7. Полтавская, М. Б. Социальное предпринимательство как идея и как процесс: взгляд некоммерческих организаций / М. Б. Полтавская // Вестник Волгоградского государственного университета. Серия 7, Философия. Социология и социальные технологии. - 2015. - № 3 (29). - С. 136-150.

8. Dacin, M. Social entrepreneurship: Acritique and future directions / M. Dacin, P. Dacin, P. Tracey // Organizational Science. - 2011. - Vol. 22 (5). P. 1203-1213.

9. Mair, J. Social entrepreneurship research: A source of explanation, prediction, and delight / J. Mair, I. Marty// Journal of World Business. - 2006. Vol. 41. - P. 36-44.

10. Murphy, P. Model of Social Entrepreneurial Discovery / P. Murphy, S. A. Coombes // Journal of Business Ethics. - 2008. - Vol. 87 (3). - P. 325-336.

11. Short J. C. Research in social entrepreneurship: past contributions and future opportunities / J. C. Short, T. W. Moss, G. T. Lumpkin // Strategic Entrepreneurship Journal. - 2009. - Vol. 3, № 2. - P. 161-194.

\section{REFERENCES}

1. Vasilyeva E.G. "Sotsialnoe gosudarstvo" i novaya model sotsialnoy politiki v Rossii ["The Welfare State" and a New Model of Social Policy in Russia]. Vlast, 2008, no. 11, pp. 27-30.

2. Grishina Ya.S. Sravnitelno-pravovoe issledovanie sotsialnogo predprinimatelstva $\mathrm{v}$ stranakh Ameriki i Evropy [Comparative Legal Study of Social Enterpreneurship in the Countries of America and Europe]. Vestnik Permskogo universiteta. Yuridicheskie nauki, 2012, no. 2 (16), pp. 111-121.
3. Kadol N.F. Sotsialnoe predprinimatelstvo $v$ rynochnoy ekonomike [Social Entrepreneurship in the Market Economy]. Bryansk, Delta Publ., 2009. $148 \mathrm{p}$.

4. Kalugina T.G. Sotsialnoe predprinimatelstvo kak faktor regionalnogo razvitiya (teoriya i praktika) [Social Entrepreneurship as a Factor of Regional Development]. Regiony i regionalnoe razvitie. Seriya «Politologiya. Religiovedenie», 2012, no. 9, Part 2, pp. 92-102.

5. Komitet po delam territorialnykh obrazovaniy, vnutrenney i informatsionnoy politiki Volgogradskoy oblasti. Informatsiya [The Committee for Local Communities and Information Policy of the Volgograd Region. Information]. URL: http:// uprt.volgograd.ru/current-activity/statistics/ information. (accessed November 20, 2017).

6. Moskovskaya A.A. Sotsialnoe predprinimatelstvo $v$ Rossii $i v$ mire: praktika $i$ issledovaniya [Social Entrepreneurship in Russia and Worldwide: Practice and Research]. Moscow, NIU VSHE Publ., 2011.288 p.

7. Poltavskaya M.B. Sotsialnoe predprinimatelstvo kak ideya i kak protsess: vzglyad nekommercheskikh organizatsiy [Social Entrepreneurship as an Idea and as a Process: a View of Non-Profit Organizations]. Vestnik Volgogradskogo gosudarstvennogo universiteta. Seriya 7. Filosofiya. Sotsiologiya i sotsialnye tekhnologii [Science Journal of Volgograd State University. Philosophy. Sociology and Social Technologies], 2015, no. 3(29), pp. 136-150.

8. Dacin M., Dacin P., Tracey P. Social entrepreneurship: A critique and future directions. Organizational Science, 2011, no. 22 (5), pp. 1203-1213.

9. Mair J., Marty I. Social entrepreneurship research: A source of explanation, prediction, and delight. Journal of World Business, 2006, no. 41, pp. 36-44.

10. Murphy P., Coombes S. A. Model of Social Entrepreneurial Discovery. Journal of Business Ethics, 2008, no. 87 (3), pp. 325-336.

11. Short J.C., Moss T.W., Lumpkin G.T. Research in social entrepreneurship: past contributions and future opportunities. Strategic Entrepreneurship Journal, 2009, vol. 3, no. 2, pp.161-194.

\section{Information about the Authors}

Elena G. Vasilyeva, Candidate of Philosophical Sciences, Associate Professor, Department of Sociology, Volgograd State University, Prosp. Universitetsky, 100, 400062 Volgograd, Russian Federation, vasilievaeg@yandex.ru, socpol@volsu.ru.

Mariya B. Poltavskaya, Candidate of Sociological Sciences, Associate Professor, Department of Sociology, Volgograd State University, Prosp. Universitetsky, 100, 400062 Volgograd, Russian Federation, poltavskaya@volsu.ru, socpol@volsu.ru. 


\section{СОЦИОЛОГИЯ И СОЦИАЛЬНЫЕ ТЕХНОЛОГИИ}

\section{Информация об авторах}

Елена Геральдовна Васильева, кандидат философских наук, доцент кафедры социологии, Волгоградский государственный университет, просп. Университетский, 100, 400062 г. Волгоград, Российская Федерация, vasilievaeg@yandex.ru, socpol@volsu.ru.

Мария Борисовна Полтавская, кандидат социологических наук, доцент кафедры социологии, Волгоградский государственный университет, просп. Университетский, 100, 400062 г. Волгоград, Российская Федерация, poltavskaya@volsu.ru, socpol@volsu.ru. 